\title{
Sezen Tan Anısına
}

\section{In Memory of Sezen Tan}

\section{Sema Tutumel Ayhan*}

$\ddot{O} z$

Benden bir yazı istendiğinde yoğun duygularla adeta içim titredi... Hala taptaze olan anılarım gözümün önünden akıp geçti... Ikinci ablam olarak tanımladığım sevgili Sezen Hanımın ardından yazı yazmak ne kadar da zor olacaktı... Yazmaya başlayınca baktım ki içerik çok duygusal, anılara dönük akıp gidiyor... Engel olamadım kendime... İçimden geldiğince, samimi, içten, düşüncemde olanlarl, hissettiklerimi yazdım... Ve bu yazı; içten, samimi, olduğu gibi ve hissettiğim gibi oluşuverdi... Anahtar Sözcükler: Sezen Tan: Hacette Üniversitesi Kütüphanesi: Türk kütüphaneciliği.

\begin{abstract}
I was touched deeply when I was asked to write an article. I thought it would make me feel all the feels... All my memories which are still alive flashed before my eyes... Imagine how it would be difficult to write about beloved Ms. Sezen, who I considered my second sister... When I started writing, I found that the content was very emotional and it flowed into memories of our past... I couldn't help myself... I wrote sincerely what I thought and what I felt... And this sincere writing has appeared in which what I felt was revealed completely...
\end{abstract}

Keywords: Sezen Tan; Hacettepe Üniversitesi Library; Turkish librarianship.

Daha İki yıl önce kaybettiğim ve hala gün gün dalga dalga gelen, kendi sevgili ablamın acısı henüz taze iken, benim için bir ikinci abla olan Sezen Hanımın acısını da yaşamak doğrusu bana çok ağır geldi... Hem de; hiç beklemediğimiz bir anda, iyileşeceği umudunu taşıdığımız bir süreçte... Adeta yıldız gibi kayıp gitti yaşamlarımızdan...

Her sabah en önce onun günaydın mesajları ile karşılaşırdım. Hiç aksatmazdı. Mesajını görmek, varlığını hissetmek gibiydi... Mutlu olur, huzur bulurdum. Sonra birden günaydın mesajları kesiliverdi 2021'in Şubat ayında. Durumu öğrendiğimde hemen aramış, abla kardeş duygusallığı içinde, kelimelerin boğazımızda düğümlendiği, sesimize hâkim olamadığımız ve en önemlisi benim için çok özel, çok duygusal bir telefon görüşmesi yapmıştık. Hafta başı tedaviye başlayacakmış... Bu konuyla ilgili duygularını

\footnotetext{
* Balıkesir Üniversitesi Kütüphane ve Dokümantasyon Daire Başkanı görevinden 2020 yılında emekli olmuştur. E-Posta: tutumelsa @gmail.com ; özgeçmiş: http://kutuphane.balikesir.edu.tr/dosya/cv.pdf Retired from Head of Balıkesir University Library in 2020. E-Mail: tutumelsa@gmail.com
}

Geliş Tarihi-Received: 19.11.2021

Kabul Tarihi - Accepted: 20.11.2021

Yayımlanma Tarihi - Published: 30.12.2021 
paylaşmıştı benimle. Kaygıllydı... Benzer bir tedavi nedeni ile kendi ablamda da yaşamış olduğum deneyimler doğrultusunda kendimce moral vermeye çalışmıştım ona... Sonraki günlerde ise birkaç kez daha telefon görüşmemiz oldu... Hep umut içindeydim. Sezen hanım güçlü bir kadındı, pes etmezdi... Hiç bir şeyden şikâyetçi olmazdı. Hep pozitif bakardı yaşama, olaylara. Bunu da yenecekti... Kötü anılar geride kalacaktı ve yeniden güzel günlerde birlikte olacaktık. Bir süredir planladığımız üzere... Ama bu kez böyle olmadı... 27 Ağustos 2021 de o acı haberi, hem de hiç beklemediğimiz kadar erken ve hızlı aldık. Bu yoksunluğu ve acıyı yaşamak kolay olmayacak elbette.

Sevgili Sezen hanımla tanışmam, Hacettepe Tıp Merkezi Kütüphanesinde işe başladığım 1978 yılına dayanır. İş arkadaşlığı içinde başlayan ilişkimiz; giderek yakın arkadaşlığa ve sonunda dostluğa ve abla kardeş ilişkisine dönüşmüştü. Hiç eksilmeden ama hep saygıll, hep sevgi içinde. Birbirimizin yaşamlarındaki değişiklikler ve gelişmeleri, acıları, mutlulukları yakından takip ederek... Paylaşarak... Sezen hanım; iş yaşamında başarılı, güçlü ve kararlı kişiliği, adil değerlendirmeleri olan, çalışma arkadaşlarına karşı destekleyici tavırlar sergileyen iyi bir yönetici, güvenilir bir dost, vefakâr, mütevazı, çevresindeki kişilere ve onların yaşamlarına duyarlı, paylaşımcı, yol gösterici kişiliği ile hem hafizamda yer etmiş hem de yaşamımda her zaman çok önemli yeri olmuştur. Düşündüm de; kendisinden meğer ne kadar çok şey öğrenmişim yaşama, insanllğa ve dostluğa dair...

Çalışma yaşamımda bana her zaman destek olmuş, ufkumu açmıştır Sezen Hanım. Yeni kişilerle tanışmama katkı sağlamış, yolumu açmış, zor kararlarda yapıcı fikirleri ile yol göstererek cesaret vermiş ve bilgi birikimlerini, deneyimlerini, gözlemlerini her zaman paylaşmiştır.

Pek çok kongrede, toplantıda birlikte olma şansı yakalamış bir kişi olarak paylaştığımız güzel anıları, sıcak değerli ortamları, unutulmaz hoş sohbetleri büyük bir mutlulukla hatırlıyor ve kendim için büyük bir şans olarak görüyorum. Ne zaman bir etkinlik olsa mutlaka yakın olurduk birbirimize... Beni yakınına çeker, yalnız bırakmaz, gerektiğinde cesaret ve destek verir, kendimi güvende hissetmeme yardımcı olurdu... Dedim ya; "ikinci ablamdı" o benim...

Yalnızca iş yaşantımızla sınırlı değildi sıcak ilişkimiz. S1k sık telefonla konuşurduk... Koşuşturmalarla ve bazen de sorunlarla akıp giden yaşamlarımız içinde, arama sıklığımız istemeden uzasa bile mutlaka bir yolunu bulur sesini duyurur, varlığını hissettirirdi. O beni asla unutmazd1...

Anımsadığım, benim için çok anlamlı ve özel bir anım var ki o da; evlenip Balıkesir'e gelişimden kısa bir süre sonra, beklenmedik bir anda, iş yerimde (Balıkesir Üniversitesi) beni ziyarete gelmesi olmuştur. Bu ziyaret beni hem çok mutlu etmiş, hem çok sevindirmiş hem de inanılmaz gururlandırmıştı. Beni unutmamıştı... Yakınımdaki bir ilde katıldığı toplantı sonrası yolunu Balıkesir'e çevirmiş beni görmeye gelmişti. Meslektaşlarımdan ve arkadaşlarımdan uzakta ve eski çevreme, arkadaşlarıma özlem duyduğum bir süreçte, kendimi yabancı hissettiğim yeni ortam ve yeni insan profiline alışma aşamasında iken, aniden sevdiğim, güvendiğim, yakın hissettiğim bir dostumu, yanımda görmek bana adeta ilaç gibi gelmiş, hasretimi gidermişti. Bu zarif ve nazik ziyaretin anılarımdaki yerini ve anlamını hiç unutamam...

Onun sıcak dostluğunu, vefakârlığını unutamayacağım bir diğer anım da; babamın cenaze törenine aittir. Rahmetli babamı kaybettiğim haberini Almanya' da iken almış ve cenaze 
için geri dönmüş, henüz hiç bir arkadaşımla, dostumla bu acı haberi paylaşma firsatım olmamıştı... Ama Sezen Hanım duyarlılığı ve vefası ile gazete ilanından öğrendiği acı haberi görür görmez yanıma koşmuştu. Onu birden yanımda görmenin o andaki şaşkınlık dolu mutluluğunu anlatamam... Acımı paylaşmak ve destek olmak için yakınımdaydı. 43 yıllık beraberlik, arkadaşlık, dostluk sürdü gitti... Ac1 tatlı olayları, mutlu, güzel, eğlenceli anları paylaştık. Birbirimizden hiç kopmadık.

En son beraberliğimiz, 2018 yılında üç güzel dostumun beni kırmayarak; (Sezen, Nazlı, Nazan) Asos’taki evimize gelerek bana böyle bir mutluluğu yaşama firsatını vermiş olmalarıyla gerçekleşti. Üç güzel insan, üç güzel arkadaş, üç özel insan, üç güzel dostla geçirdiğimiz hafta sonu unutulmazdı. Bursa da başlayan beraberliğimizde; Balıkesir, Kaz dağları, Yeşil Yurt, Kozlu, Sivrice, Sokak Ağzında hem gezdik, hem çok güldük, eğlendik, denize girdik, yürüdük... Çok ama çok mutlu olduk... Dostluğumuzu pekiştirdik, anılarımızı tazeledik, yeni anılar biriktirdik. Yeniden ve yeni rotalarda buluşmak üzere planlar yaptık, kararlar aldık.

İyi ki gelmişler, iyi ki anılarımıza kaydetmişiz o güzel paylaşımları... Rüya gibiydi... Öyle güzeldi... Öyle içten ve sevecen bir beraberlikti ki hala anılarımda capcanlı durmaktalar... Ama işte birden bire her şey bitti... Aramızdan bir güzel insan ayrıldı gitti; yokluğunu ve yoksunluğunu her an hissettiğim. İlk anda aklıma gelen anılar, izler ve anımsadıklarımı düşününce; "'kim bilir"' diyorum, "daha ne çok iz bırakmıştır diğer dostluklarında ve arkadaşlıklarında', ... Öğrenmeye değer...

Sevgili canım Sezen Hanım, sevgili ablam, seni unutmam mümkün değil. Bizlere çok kısa geldi yaşamın. Şairin dediği gibi her ölüm erken ölümdür... Yaşamın boşuna olmadı. Gördüm ki çok kişiye dokunmuş, çok insan biriktirmişsin. $\mathrm{Ne}$ mutlu... İyi ki benimde hayatımda olmuşsun, iyi ki güzel anılar biriktirmişiz. Her zaman mutlulukla hatırlayacağım güzel anları paylaşmışız. Her zaman kalbimde, anılarımda yaşayacaksın. Güzel, zarif, fedakâr, verici, hassas, öz verili dost... Işıklarda yat. Seni tanımış olmaktan çok mutluyum. Seni her zaman çok sevdim...

\section{Kız Kardeşin}

12.11.2021

Balıkesir
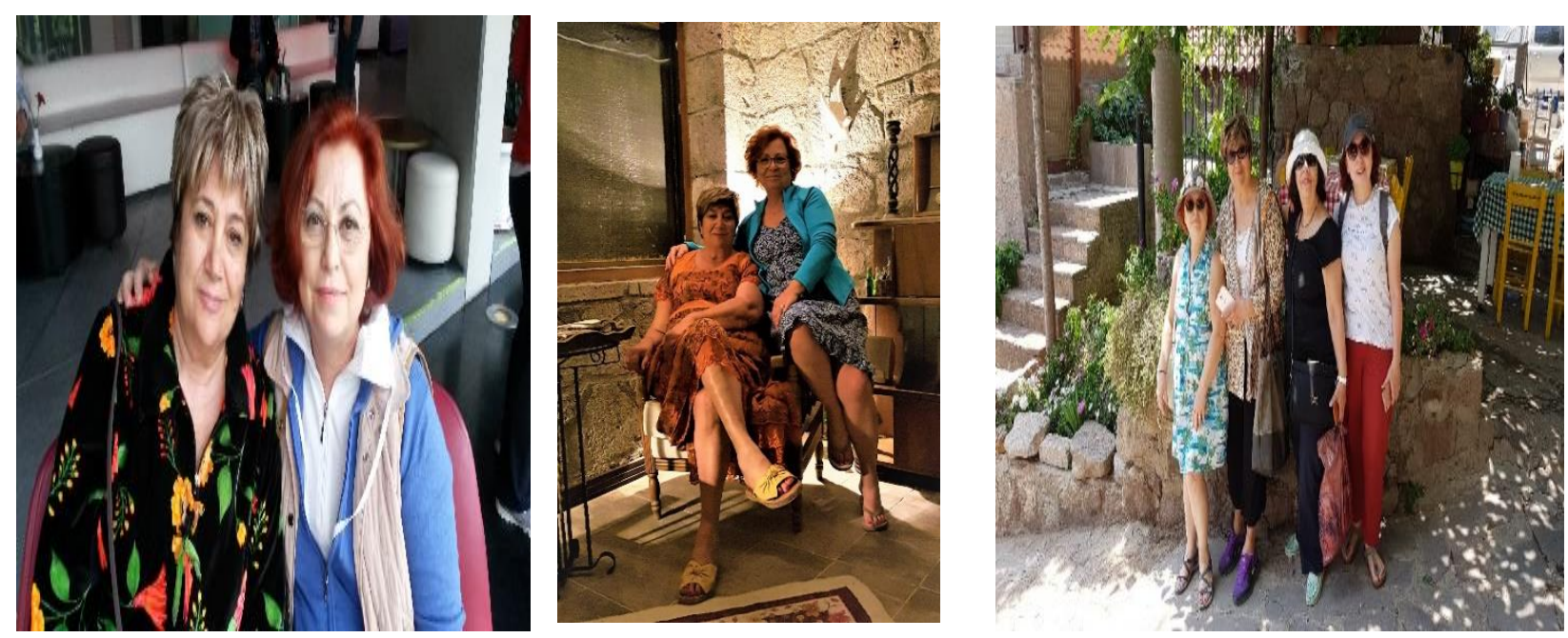